Review Article

\title{
Optimal Power Flow Techniques under Characterization of Conventional and Renewable Energy Sources: A Comprehensive Analysis
}

\author{
Baseem Khan $^{1}$ and Pawan Singh ${ }^{2}$ \\ ${ }^{1}$ School of Electrical and Computer Engineering, Hawassa University Institute of Technology, Hawassa, Ethiopia \\ ${ }^{2}$ School of Informatics, Hawassa University Institute of Technology, Hawassa, Ethiopia \\ Correspondence should be addressed to Baseem Khan; baseem.khan04@gmail.com
}

Received 16 June 2017; Revised 1 September 2017; Accepted 14 September 2017; Published 3 December 2017

Academic Editor: Daniela Proto

Copyright (C) 2017 Baseem Khan and Pawan Singh. This is an open access article distributed under the Creative Commons Attribution License, which permits unrestricted use, distribution, and reproduction in any medium, provided the original work is properly cited.

\begin{abstract}
The exhaustive knowledge of optimal power flow (OPF) methods is critical for proper system operation and planning, since OPF methods are utilized for finding the optimal state of any system under system constraint conditions, such as loss minimization, reactive power limits, thermal limits of transmission lines, and reactive power optimization. Incorporating renewable energy sources optimized the power flow of system under different constraints. This work presents a comprehensive study of optimal power flows methods with conventional and renewable energy constraints. Additionally, this work presents a progress of optimal power flow solution from its beginning to its present form. Authors classify the optimal power flow methods under different constraints condition of conventional and renewable energy sources. The current and future applications of optimal power flow programs in smart system planning, operations, sensitivity calculation, and control are presented. This study will help the engineers and researchers to optimize power flow with conventional and renewable energy sources.
\end{abstract}

\section{Introduction}

The OPF in power system is an optimization problem under various constraints. It is practically significant and wellexplored subfield of constrained optimization. The important feature of OPF is the presence of the load flow equations in the set of equality constraints. Carpentier [1] introduced the OPF problem in 1979. Carpentier introduced OPF as an extension to the problem of optimal economic dispatch (ED) of generation in traditional power systems. Carpentier's key contribution was the inclusion of the electric power flow equations in the ED formulation. OPF techniques are traditional and metaheuristic based. Figure 1 shows the classification of traditional and metaheuristic techniques.

Further, due to large integration of renewable energy sources in conventional power system, incorporation of uncertainties in OPF calculation is essential.

OPF largely depends on static optimization method for minimizing a scalar optimization function. Dommel and
Tinney [2] introduced OPF in 1968, for minimization purpose, in which the first-order gradient algorithm is subject to equality and inequality constraints. Momoh et al. [3] utilized OPF to resolve the problems of deregulated electrical industry. Further, authors have used OPF to solve problems of vertical electricity market.

In this paper, authors present a comprehensive study of optimal power flow methods. Section 2 presents the review of OPF methods with conventional energy sources. In Section 3, authors reviewed OPF methods with renewable energy sources. Section 4 presents a comparative analysis between different OPF methods followed by the conclusion.

\section{OPF for Power System with Conventional Energy Sources}

There are various methods to solve the problem of optimal power flow with conventional energy sources. Some of them are as follows. 


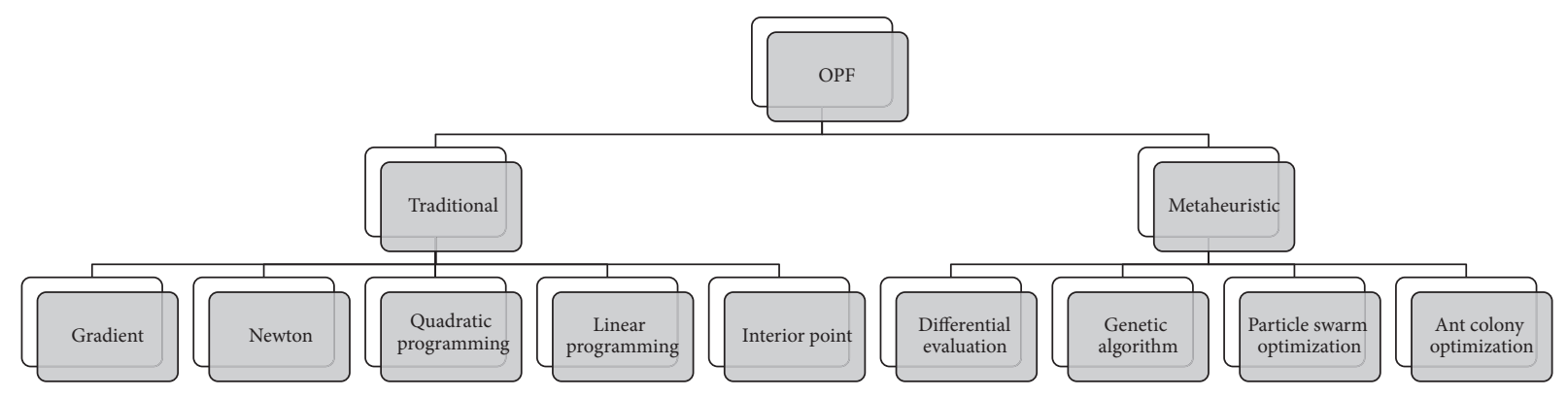

FIGURE 1: Classification of OPF methods.

2.1. Mathematical Methods. Classical mathematical methods (gradient, Newton's, linear, and integer programming, etc.) allow the finding of optimal solutions of real-world problems.

2.1.1. Gradient Method. In Jan 2004, Sun et al. [4] proposed a penalty-based scheme for OPF with transient stability, in which adjoint equation technique calculates the gradient of the penalty term related to the stability constraints. This adjoint equation approach greatly reduces the computational cost.

2.1.2. Newton Method. In 1984, David et al. [5] presented a method to solve classical OPF problem with a nonseparable objective function. The classical OPF is a problem with controllable variables, which is regulated to optimize an objective function, by satisfying physical and operating limits. In 2007, Pizano-Martinez et al. [6] presented a Newton's algorithm based model of a voltage source converter-high voltage direct current (VSC-HVDC) system, which is fit for OPF solutions. The VSC-HVDC's capability to deliver the independent control of converter's AC voltage magnitudes and phase angles is well represented by the model, which permits active and reactive power control separately for system regulation. In 2012, Zhao et al. [7] proposed a variant of primaldual interior point method (PDIPM) algorithm based on the continuous Newton's method to improve the robustness of PDIPM. Newton's algorithm in PDIPM is exchanged with continuous Newton's method. The developed method indicates good stability and exceptional ability to converge. In 2000, Ambriz-Perez et al. [8] presented advanced load flow models for the static VAR compensator (SVC). The models are merged into current load flow (LF) and OPF Newton's algorithm. A complete SVC susceptance and firing angle models are suitable for conventional and optimal power flow analysis. In 2009, Milano [9] presented a continuous version of Newton's method for solving the power flow problem. It has two main contributions: the first, a general framework for applying efficient numerical integration techniques to solve ill conditioned or badly initialized power flow cases and the second, a formal classification of the existing numerical schemes for solving the power flow problem.

2.1.3. Linear, Nonlinear, and Semidefinite Programming. In 1998, Wei et al. [10] presented a new interior point nonlinear programming algorithm for OPF, which is based on the uneasy Kurush-Kuhn-Tucker (KKT) conditions of the original problem but not on a logarithmic barrier function method. Through the concept of centeringdirection, the interior point method is stretched to classical power flow (C$\mathrm{PF}$ ) and approximate OPF (A-OPF) problems. In 2008, Bai et al. [11] presented a new solution using the semidefinite programming (SDP) technique to solve the OPF. The developed method includes reformulating the OPF problems into SDP model and developing an algorithm of interior point method (IPM) for SDP. Based on SDP, the OPF problem is solved by primal-dual interior point algorithms, which possess super linear convergence. In 1994, Granville [12] presented an application of an interior point method based on the primaldual algorithm to optimal reactive power dispatch (ORPD), which is a large-scale nonconvex nonlinear programming problem with nonlinear constraints. In 2005, Zhang et al. [13] presented a nonlinear interior point optimal power flow (OPF) method based on a current mismatch formulation in rectangular coordinates.

2.1.4. Uncategorised Mathematical Techniques. In 2015, Abdelouadoud et al. [14] presented a second-order cone (SOC) relaxation algorithm to solve OPF based on a branch flow model of a radial and balanced distribution system. In 2016, Baran and Fernandes [15] presented a three-phase OPF, which includes the mutual impedances in order to minimize the losses of system. In 2016, Garces [16] presented a quadratic approximation for OPF in power distributions systems. The proposed method is based on a linearized load flow, which is effective for power distribution systems as well as threephase unbalanced operation. In 2015, Emily Manoranjitham and Shunmugalatha [17] presented a process to solve OPF in the power system, which utilized UPFC. This UPFC recovers power transfer capability and transient stability as well as diminishing the transmission loss and fuel cost of generation. In 2016, Xu et al. [18] presented the preventive-corrective security-constrained optimal power flow (PCSCOPF) to accomplish the best coordination between the preventive control (PC) and corrective control (CC) by considering the probabilistic nature of the contingencies and cost of $\mathrm{CC}$ as well as other binding constraints. In 2015, Zhang et al. [19] presented the optimal model of carbon energy combined flow (OCECF) which is solved by a new estimated multiobjective solution (AIMS) $Q(\lambda)$ learning. The carbon emissions, fuel cost, active power loss, voltage deviation, and carbon 
emission loss are selected as the optimization objectives. In 2015, Zhao et al. [20] proposed a voltage stability constrained dynamic optimal reactive power flow (VSC-DORPF) model. It decreases daily network losses, improves voltage quality, and enhances voltage stability of power system. In 2016, Wang et al. [21] presented a mathematical technique to solve the corrective risk-based security-constrained optimal power flow (CRB-SCOPF) model, which considers the system's corrective capabilities after contingency occurred. The proposed method applies Lagrangian relaxation to the system risk constraints and then applies benders decomposition to the remaining Lagrangian subproblem.

2.2. Metaheuristic Algorithms. Metaheuristic techniques are powerful and flexible search methodologies that have successfully tackled practically difficult problems. Heuristic and metaheuristic algorithms seek to produce good quality solutions in reasonable computation times that are good enough for practical purposes.

2.2.1. Genetic Algorithm. In 2002, Bakirtzis et al. [22] presented the OPF, which is a nonlinear, nonconvex, large-scale, static optimization problem based on an enhanced genetic algorithm (EGA). For the solution of OPF, both continuous and discrete control variables are used. In 1995, Lee et al. [23] presented an enhanced simple genetic algorithm, used for reactive power system planning. Further, a new population selection and generation method is proposed, which uses Bender's cut method. In 1998, Lee [24] presented a comparative study for three evolutionary algorithms (EAs) to solve the optimal reactive power planning (ORPP) problem. The ORPP problem is decomposed into $P$ and $Q$ optimization modules, and the evolutionary algorithms optimize each module in an iterative manner to obtain the global solution. In 2006, Todorovski and Rajicic [25] presented a new method to solve the OPF problem by using genetic algorithm. It depends on the application of new initialization procedure, which utilizes voltage angles at generator-buses as control variables to achieve voltages at load-buses with less computation.

2.2.2. Particle Swarm Optimization. In 2002, Abido [26] presented particle swarm optimization (PSO) algorithm based an efficient and reliable approach to solve the OPF problem. The proposed approach employs the global and local investigation capabilities of PSO to examine the optimal setting of control variables. Different objective functions have been considered to minimize the fuel cost, improve the voltage profile, and enhance voltage stability. In 2006, Vlachogiannis and Lee [27] presented three types of PSO algorithms: the enhanced general passive congregation (GPAC), local passive congregation (LPAC) with limitation factor approach based on the passive congregation operator, and the CA based on the coordinated aggregation operator. The proposed PSO algorithms and the conservative interior point OPF based algorithm competed in the optimization problems of reactive power and voltage control. In 2005, Esmin et al. [28] presented an approach to optimize the power loss by using PSO algorithm and improved the PSO to the hybrid PSO (HPSO) algorithm. The proposed approach employs local and global capabilities to search the solution of optimal loss reduction by installing the shunt reactive power compensator. In 2008, Zhang and Liu [29] presented a formulation of multiobjective reactive power and voltage control problem. The multiobjective problem has been solved by means of fuzzy optimization strategy and fuzzy adaptive particle swarm optimization (FAPSO). The factors are active power loss, voltage deviation, and the voltage stability index of the system. In 2009, Al-Rashidi and El-Hawary [30] presented a complete formulation of dissimilar particle swarm optimization (PSO), which is applied to solve optimization problems in power systems. In 2016, Su et al. [31] presented an optimization based sequential strategy and multiobjective optimization based real-time strategy for the optimal placement and control of delta-connected switched capacitors. Considering load variations, a complete optimization for capacitor placement is formulated to increase the net annual returns from network loss reduction and capacity release. Further, a sequential strategy based on loss sensitivity analysis is presented for efficient capacitor placement on large-scale unbalanced distribution networks. In 2008, Valle et al. [32] presented a comprehensive overview of the basic concepts of PSO and its variants. In addition, a comprehensive study on different power system problems, which is solved by PSO, is presented. In 2016, Singh et al. [33] employed an aging leader and challengers PSO (ALC-PSO) to solve different types of OPF problem of power system with several types of complexities and capacities.

2.2.3. Uncategorised Metaheuristic and Search Algorithms. In 2011, Niknam et al. [34] presented a multiobjective improved shuffle frog-leaping algorithm (SLFA) to solve the OPF emission problem in power systems considering both economic and environmental issues. The proposed technique produces optimal values, taking into account different objectives, including the best cost and the best emission. In 2014, Ghasemi et al. [35] presented chaotic invasive weed optimization (CIWO) algorithms based on chaos and examine its performance for optimal settings of OPF and its control variables. In 2016, Abaci and Yamacli [36] presented a differential search based optimization method to solve various types of problems including complex, single, and multiobjective functions within the constraints concerning optimal power flow (OPF). In 2016, Acharjee [37] presented the self-adaptive differential evolutionary (SADE) algorithm for increasing and controlling the power flow using unified power flow controller (UPFC) under practical security constraints (SCs). In 2016, Ardeshiri Lajimi and Amraee [38] presented an artificial neural network (ANN) based transient stability constrained optimal power flow (TSCOPF) formulation by using imperialist competitive algorithm (ICA). In order to increase the rotor angle transient stability of power system against large disturbances, critical clearing time is used as the transient stability index. In 2016, Ayan and Kiliç [39] presented the solution of OPF problem for biterminal highvoltage direct current (HVDC) power systems by using backtracking search algorithm (BSA). To show the applicability 
and efficiency of BSA, three different test systems are utilized. In 2016, Daryani et al. [40] presented an adaptive group search optimization (AGSO) algorithm for solving optimal power flow (OPF) problem. In 2015, Mahdad and Srairi [41] presented a new approach of power system planning which is based on hybrid firefly algorithm (FFA) and pattern search (PS) algorithm and supported with brainstorming rules to minimize total fuel cost, power losses, and voltage deviation. In 2015, Mukherjee [42] presented chaotic krill herd algorithm (CKHA) to solve the OPF problem of power system with different objective functions and to increase the performance of basic KHA method. In 2016, Mukherjee and Mukherjee [43] presented a novel opposition based Krill herd algorithm (OKHA), a metaheuristic algorithm, to resolve the OPF problem of power system incorporated with flexible AC transmission systems (FACTS) devices. In 2016, Pandiarajan and Babulal [44] presented a fuzzy logic based harmony search algorithm (FHSA) to solve optimal power flow problem of security enhancement in power system. The minimization of fuel cost and severity index objectives are considered. The fuel cost is minimized by changing generator active power, generator bus voltage magnitude, transformer taps, and VAR of shunts. In 2016, Prasad and Mukherjee [45] presented a symbiotic organisms search (SOS) metaheuristic algorithm to solve the OPF problem of power system equipped with FACTS devices. In 2015, Ramesh Kumar and Premalatha [46] presented an adaptive real coded biogeography-based optimization (ARCBBO) method to solve different objective functions of OPF problems with several physical and operating constraints. The different objectives are fuel cost minimization, active power loss minimization, emission minimization, voltage profile, and voltage stability enhancement. In 2015, Venkateswara Rao and Nagesh Kumar [47] utilized BAT algorithm to minimize real power losses in a power system. Further optimal power flow problem is solved with unified power flow controller. In 2015, Yuan et al. [48] presented an upgraded artificial bee colony algorithm with quantum theory and chaotic local search operator (QCABC) to solve the OPF problem.

\section{OPF for Power System with Renewable Energy Sources}

3.1. Distributed Generation (DG). In 2011, Amanifar and Hamedani Golshan [49] presented the PSO algorithm to find the optimal locations and sizes of DGs, with an objective to minimize the total cost of the system, real power loss, and the number of DGs to be installed. In 2005, Harriso and Wallace [107] presented government led targets and incentives for increasing the capacity of distributed generation connecting to distribution networks. In 2012, Pazheri et al. [50] presented economic/environmental dispatching (EED) problem formulation for a hybrid system, which includes thermal generating units, solar, wind, and renewable storage. Analysis is carried out using MATLAB simulation for a high irradiation solar region. In 2014, Nick et al. [51] presented the optimal allocation of dispersed storage systems (DSSs) in active distribution networks (ADNs) by describing a multiobjective optimization problem to find the optimal trade-off between technical and economic goals. In 2010, Atwa et al. [52] proposed a probabilistic planning technique for optimally allocating different types of $D G$ (i.e., wind DG, solar DG, and biomass DG) in the distribution system to minimize annual energy losses. In 2013, Georgilakis and Hatziargyriou [108] presented a comprehensive description of different models and optimization methods to solve the optimal DG placement (ODGPP) problem, for examining as well as categorising current and future research approaches in this field. In 2014, Gill et al. [53] presented a broad dynamic optimal power flow (DOPF) framework for the active network management (ANM) schemes. ANM technologies are focused on intertemporal effects. The DOPF is modelled for renewable energy curtailment, energy storage, and flexible demand. In 2015, Jabr et al. [54] presented a sparse formulation for the affinely adjustable robust counterpart (AARC) of the multiperiod OPF problem with RES and storage. In 2012, Moradi and Abedini [55] presented a combined method to solve location and capacity problems for DG. This method utilized GA and PSO to determine the location and capacity of DG, respectively. In 2011, Sortomme and El-Sharkawi [109] presented the potential profits and effects of unidirectional vehicle to gird (V2G). In 2007, Yang et al. [56] presented the hybrid solar wind system optimization sizing model (HSWSO) to optimize the capacity sizes of hybrid solar wind power generation systems employing a battery bank. In 2011, Atwa and El-Saadany [57] presented a probabilistic planning technique for optimally fulfilling wind-based distributed generation (DG) in distribution systems to minimize annual energy loss. In 2007, Ashok [110] discussed various system apparatus for hybrid energy system to improve a universal model and found an optimal combination of energy components for supplying rural community. In 2016, Bouhouras et al. [111] presented the optimization concerning the placement and sizing of DG units in distribution networks (DNs) for loss minimization. In 2015, Azizipanah-Abarghooee et al. [112] presented a probabilistic OPF problem for the system consisting of the thermal units (TUs), wind power plants (WPPs), photovoltaic cell (PV), and combined heat and power (CHP). In 2016, Wei et al. [58] proposed an integration technique of DG based on stochastic optimal power flow (S-OPF). A low-cost optimal model of DG integration for Distribution System Operators (DSOs) is modelled. In 2013, Lin and Chen [59] presented a distributed and parallel OPF (DPOPF) algorithm. Additionally, a Petri net (PN) based computational synchronization mechanism is proposed to solve OPF smart grid transmission system (OPFSG) problem. In 2015, Summers et al. [60] presented a stochasticmultiperiod OPF problem, for which a family of convex rough calculations is used to trade-off cost against security in different ways. In 2016, Tazvinga et al. [113] presented an optimal model of a photovoltaic-diesel-battery (PDB) based hybrid energy management system to reduce both fuel costs and battery wear costs. It also discovers the optimal power flow, photovoltaic power availability, battery bank state of charge, and load power demand. In 2016, Chen et al. [61] presented a PSO based optimal power management method to consider uncertain driving conditions for plug-in hybrid 
electric vehicles (HEVs). In 2015, Ma et al. [114] presented a technoeconomic analysis of the standalone hybrid solarwind-pumped storage system for an isolated microgrid. In 2017, Sichilalu et al. [62] presented an optimal control (OC) model of a heat pump water heater $(\mathrm{HPWH})$, which is supplied by a wind generator-photovoltaic-grid system. The objective function is energy cost minimization, which considers the time-of-use electricity tariff.

3.2. Microgrid. In 2011, Sanseverino et al. [63] presented an execution monitoring and replanning approach to solve the optimal generation dispatch problem in a smart grid through the minimization of carbon emissions and production costs as well as improve the quality. In 2015, Shi et al. [64] presented an online energy management strategy (EMS) for real-time operation of microgrids. In 2013, Dall'Anese et al. [65] presented the numerical tests. The main role of the proposed approach is to achieve the globally optimal solution of the original nonconvex optimal power flow. In 2012, Battistelli et al. [115] presented an optimization tool for energy management within small energy systems incorporated with V2G systems. In 2011, Chen et al. [66] presented a smart energy management system (SEMS) to organize optimally the power production of DG sources and energy storage system (ESS), and, additionally, minimize the operational costs of microgrids. In 2012, Liang et al. [67] presented a wide-area measurement based dynamic stochastic optimal power flow (DSOPF) control algorithm using the adaptive critic design (ACD) technique. In 2013, Levron et al. [68] presented the optimal energy management system of storage devices in grid-connected microgrids. Stored energy is controlled to balance the loads and renewable sources as well as minimize the total cost of energy at the point-of-common-coupling (PCC). In 2011, Moghaddam et al. [69] presented a multiobjective adaptive modified PSO (AMPSO) optimization algorithm to solve the multioperation management problem in a typical MG with renewable energy sources (RESs). In 2010, Morais et al. [70] presented the operational optimization of an isolated system by a virtual power producer (VPP). The main objective is to decide the best VPP management strategy to minimize the generation costs and optimize storage charging and discharging time subjected to all operational constraints. In 2011, Tanaka et al. [116] presented an approach for optimal operation of a smart grid to minimize the interconnectionpoint power flow fluctuation. To accomplish the planned optimal operation, distributed controllable loads such as battery and heat pump are used. In 2015, Alavi et al. [71] proposed an optimal approach for operating a MG in islanded mode. The uncertainties associated with output of renewable resources and demands are demonstrated by point estimate method (PEM) and robust optimization (RO), respectively. In 2014, Bahmani-Firouzi and Azizipanah-Abarghooee [72] presented an effective outline for MG operation management studies with respect to operation, maintenance, and financial points. The fixed and maintenance cost of battery energy storage (BES) was considered in the optimization of MG studies. A robust and effective metaheuristic improved bat algorithm (IBA) approach is used to develop corrective strategies and perform least cost dispatches. In 2015, Bracale et al. [117] presented an optimal control approach for a DC microgrid (DCMG) that included dispatchable (such as microturbine) and nondispatchable (such as photovoltaic generator) generation units, a storage system, and controllable/noncontrollable loads. This approach is designed to minimize the daily total energy costs. In 2015, Gholami et al. [73] employed GA with new settings and operators, which is capable of capacitor placement in both islanded and grid-connected modes at different load levels. In 2012, Khorramdel and Raoofat [74] presented a stochastic programming approach for reactive power scheduling of a MG under the uncertainty of wind farms. A multiobjective function with goals of loss minimization, reactive power reserve, and voltage security margin maximization are optimized using a four-stage multiobjective nonlinear programming. In 2016, Lv et al. [75] proposed a multiobjective bilevel optimization algorithm. The upperlevel model defines the optimal dispatch of distribution network (DN) to accomplish minimum power loss and voltage profile. The lower-level model considers microgrids (MGs) operating cost as objective to decide the optimal operation scheme of distributed generator DGs. In 2015, Mclarty et al. [118] presented two optimization approaches for the dispatch of a multichiller cooling plant with cold-water thermal storage. The optimization objective is to decrease both cost and emission while considering real operational constraints of a plant. In 2015, Riva Sanseverino et al. [119] presented a novel OPF algorithm for islanded MG. The algorithm yields minimum losses and stable operating point with relevant droop parameters, which are used for primary voltage and frequency regulation. In 2015, Sharma et al. [76] presented a quasi-oppositional swine influenza model based optimization with quarantine (SIMBO-Q) to reduce the total operation cost of MG considering optimal size of battery energy storage.

\subsubsection{Microgrid with Renewable Energy Sources and/or Battery} Energy Storage System. Presently, batter storage system is a vital component in microgrid technology. For optimizing the investment in data centre's storage capacity, Thompson et al. [120] presented a method. In [77], Sharma et al. utilized gray wolf optimization method for finding the optimum capacity of energy storage. In [121], Krishnamurthy and Kwasinski discussed microgrid's power supply resiliency under severe conditions. Xu et al. [122] presented an engineering experience with energy storage system. For optimizing storage capacity in microgrid, Liu et al. [78] proposed an optimal coordinated planning scheme. In [123], Khodabakhsh and Sirouspour developed two different methodologies for online rolling horizon optimal control of storage system. Shen et al. [79] presented an energy management scheme for microgrid, which contains battery storage, diesel generators, PV, and wind. For optimal working of an electric vehicle parking deck, Guo et al. [80] presented a bilevel structure. For frequency control of microgrid, Hassanzadehfard et al. [124] employed battery banks as long-term storages and ultracapacitors as short-term storages. To calculate the optimal power rating and capacity of energy storage, Alharbi and Bhattacharya [125] developed an optimization model. 
3.2.2. Electric Vehicle Technology. The latest development in the field of electric vehicle technology has a great impact on microgrid operation. For renewable energy sources and vehicle to grid system integration, Melhem et al. [81] proposed a residential energy management system. Yu et al. [82] investigated a model to find the impact of electric vehicle technology on demand response mobility. For integrating electric vehicle in smart gird, Laureri et al. [126] developed an optimization technique. Paterakis et al. [83] presented an optimization model for minimizing energy procurement cost of smart household. Li et al. [84] presented an online methodology for performing cost aware scheduling. To charge electric vehicle, Yao et al. [127] presented a real-time charging scheme.

3.3. Solar. In 2012, Lin et al. [85] utilized an active power limitation strategy to diminish PV power injection during peak solar irradiation, to avoid voltage violation. In 2015, Martín [86] presented the process of a concentrated solar plant, which is based on regenerative Rankine cycle. Additionally, dry cooling technologies are optimized by using mathematical programming techniques. In 2014, Bianchi et al. [128] presented a PV/battery hybrid system, to endorse the optimal design of hybrid system in terms of PV module number, PV module tilt, and number and capacity of batteries. In 2015, Burlafinger et al. [87] utilized selective absorbers for concentrated solar power (CSP) plants to minimize thermal losses and increase the efficiency. Additionally, solar thermal absorber's potential is optimized by using selective absorption properties and temperature. In 2016, Guo et al. [88] presented the optimal ratio of turbine pressure drop to the available total pressure difference and examined it broadly using theoretical analysis and 3D numerical simulations, for solar chimney power plant (SCPP). In 2015, Ha and Vakiloroaya [129] addressed the modelling and control problem of a fully developed hybrid solar-assisted, splitsystem air-conditioner to improve the performance of an existing solar air-conditioning system. In 2013, LizarragaGarcia et al. [130] presented an optimization case study for the time-variable operation of the concentrated solar power on demand (CSPonD) solar energy receiver and thermal energy storage. In the study, the factors considered are timevariable electricity prices and electricity buy-back from the grid. In 2017, Mokheimer et al. [131] presented an integrated solar gas turbine cogeneration plant (ISGCP) which generates electricity and produces process steam at a constant rate of $81.44 \mathrm{~kg} / \mathrm{s}$ at $45.88 \mathrm{bar}$ and $394^{\circ} \mathrm{C}$ throughout the year. In addition to this, the generation of electricity is investigated for different gas turbine generating capacities. In 2014, Nazir et al. [89] presented the power flow optimization of the PV system connected to the grid. Optimization has been performed by calculating the root of the active power equation $P$ (ma, $\alpha$ ) and reactive power equation $Q$ (ma, $\alpha$ ) using Newton Raphson method. In 2016, Ntsaluba et al. [90] presented a flow-rate optimization of solar water heating system (SWHS) with specific focus placed on pump flow-rate optimization. In 2015, Wang et al. [91] presented an approach to analyse the optimal capacity and economic feasibility of a hybrid energy storage system (HESS) supporting the dispatch of a $30 \mathrm{MW}$ photovoltaic $(\mathrm{PV})$ power plant.
3.4. Wind. In 2014, Rabiee et al. [92] presented a complete OPF formulation for a power system with uncertain wind power injection through line-commutated converter high-voltage DC (LCC-HVDC) links, voltage source converter (VSC-HVDC), and doubly fed induction generators' (DFIGs). The objective is to maximize the toughness of total costs against the intermittent wind power generation using info-gap decision theory (IGDT). In 2016, Ke et al. [93] presented a new probabilistic optimal power flow (POPF) model with chance constraints that reflects the uncertainties of wind power generation (WPG) and loads. In 2014, Bienstock et al. [94] presented a technique that depends on chance constraints to limit the probability that any line (or generator) is overloaded, together with an optimal online control that accounts for controllable generator response to renewable fluctuation. In 2011, Brekken et al. [132] presented the sizing and control procedures for a zinc-bromine flow battery-based energy storage system. The results show that through an effective control and coordination of energy storage systems, the expectedness of wind plant outputs is increased and the cost of combination associated with reserve necessities is decreased. In 2013, Ghofrani et al. [95] presented an optimal placement of energy storage in a deregulated power system to minimize the hourly social cost. By the means of historical data and curve fitting, both wind and load are modelled stochastically. A GA-enhanced market-based probabilistic optimal power flow (POPF) with energy storage integration and wind generation maximizes wind power utilization over the scheduling period. In 2009, Jabr and Pal [96] presented a stochastic model of wind generation in an OPF dispatching program. The model faces the coordination of wind and thermal power while accounting for the expected penalty cost for not using all available wind power and the expected cost of utilizing power reserves because of wind power shortage. In 2016, Sedghi et al. [133] presented the planning technique for defining optimal location, capacity, and power rating of the batteries while minimizing the cost function under the technical constraints. The objective function involves the monetary factors, such as investment, operation, and reliability costs, as well as the technical penalty factor. In 2014, Sebastián et al. [97] presented a probabilistic AC optimal power flow (POPF) that takes into account load variation, wind's stochastic behaviour, and variable line's thermal rating which is usually used as a deterministic value in several studies. In 2015, Aien et al. [98] reviewed the probabilistic techniques used for probabilistic optimal power flow (POPF) and proposed a method by using the unscented transformation (UT) technique. In 2013, Arabali et al. [134] presented a technical outline to evaluate the energy storage application, optimal placement, and economic advantage, for the social cost and transmission congestion. In 2014, Chang et al. [99] presented an evolutionary particle swarm optimization (EPSO) approach for solving the OPF problem of a wind-thermal power system. In 2015, Jadhav and Roy [135] presented an optimization system to calculate the optimal operation of system containing electric vehicles and offshore wind farm connected to the grid through HVDC link. In 2015, Li et al. [100] presented the probabilistic optimal power flow for wind 
TABLE 1: Comparative analysis of different OPF techniques.

\begin{tabular}{|c|c|c|c|c|c|c|c|}
\hline \multirow[b]{2}{*}{$\begin{array}{l}\text { OPF problem } \\
\text { classification }\end{array}$} & \multicolumn{6}{|c|}{ Constraints } & \multirow[b]{2}{*}{ Assumptions } \\
\hline & $\begin{array}{l}\text { Voltage and } \\
\text { angle }\end{array}$ & $\begin{array}{c}\text { Transmission } \\
\text { line power } \\
\text { limit }\end{array}$ & $\begin{array}{c}\text { Reactive } \\
\text { power limits }\end{array}$ & Losses & $\begin{array}{l}\text { Generation } \\
\text { costs }\end{array}$ & Contingency & \\
\hline $\mathrm{AC}$ & Yes & Yes & Yes & Yes & No & No & Slack bus selection \\
\hline $\mathrm{DC}$ & No & Yes & No & Not definite & Yes & No & $\begin{array}{l}\text { Voltage magnitudes are } \\
\text { fixed }\end{array}$ \\
\hline Decoupled & Yes & Yes & Yes & Yes & Yes & No & $\begin{array}{c}\text { Interaction between } \\
\text { active and reactive } \\
\text { power is not considered }\end{array}$ \\
\hline $\begin{array}{l}\text { Security-constrained } \\
\text { economic dispatch }\end{array}$ & Yes & Yes & No & Yes & Yes & Yes & Bus voltages are fixed \\
\hline Economic dispatch & No & No & No & Conditional & Yes & No & $\begin{array}{c}\text { No transmission } \\
\text { constraints }\end{array}$ \\
\hline Security-constrained & Yes & Yes & Yes & Yes & Yes & Yes & $\begin{array}{l}\text { Assumptions regarding } \\
\text { postfault flows are there }\end{array}$ \\
\hline $\begin{array}{l}\text { Optimal reactive } \\
\text { power dispatch }\end{array}$ & Yes & Yes & Yes & Yes & Yes & No & $\begin{array}{l}\text { Convexity assumption of } \\
\text { generators' cost function }\end{array}$ \\
\hline $\begin{array}{l}\text { Metaheuristic based } \\
\text { OPF }\end{array}$ & Yes & Yes & Yes & Yes & Yes & No & $\begin{array}{l}\text { Inherent inadequacy that } \\
\text { needs further attention } \\
\text { in the future including } \\
\text { the lack of transparency, } \\
\text { knowledge extraction, } \\
\text { and model uncertainty }\end{array}$ \\
\hline
\end{tabular}

TABLE 2: Comparative analysis of traditional and metaheuristic based OPF methods.

\begin{tabular}{|c|c|c|c|}
\hline $\begin{array}{l}\text { S. } \\
\text { number }\end{array}$ & Properties & Traditional technique & Metaheuristic techniques \\
\hline (1) & Model formulation & $\begin{array}{l}\text { Model is used to simulate a system when the } \\
\text { system is not extremely complicated. }\end{array}$ & $\begin{array}{l}\text { Metaheuristic techniques try to imitate, in a very } \\
\text { simplistic way, the human cognition capability. }\end{array}$ \\
\hline (2) & Prerequisites & $\begin{array}{l}\text { Use the principles (e.g., physical laws) to derive } \\
\text { the relationships of the system. }\end{array}$ & $\begin{array}{c}\text { Dependent on data to determine the structure } \\
\text { and parameters. }\end{array}$ \\
\hline (3) & $\begin{array}{l}\text { Nonlinearity } \\
\text { integration }\end{array}$ & $\begin{array}{l}\text { Possible if prior knowledge of the nature of the } \\
\text { nonlinearity exists. }\end{array}$ & $\begin{array}{l}\text { The prior information of the nature of the } \\
\text { nonlinearity is not required. }\end{array}$ \\
\hline$(4)$ & Hypothesis & $\begin{array}{l}\text { Simplifying the problem or incorporating } \\
\text { assumptions to make model more understandable. }\end{array}$ & $\begin{array}{c}\text { No need to simplify the model and/or add } \\
\text { assumptions. }\end{array}$ \\
\hline (5) & Precision \& accuracy & Provide highest level of accuracy. & $\begin{array}{c}\text { Provide greater precision and accuracy due to less } \\
\text { chances of error. }\end{array}$ \\
\hline (6) & Efficiency & Needs more time to solve the complex problem. & $\begin{array}{l}\text { Utilized to carry out repetitive and } \\
\text { time-consuming tasks, efficiently. }\end{array}$ \\
\hline (7) & $\begin{array}{l}\text { Renewable energy } \\
\text { integration }\end{array}$ & Requires complex mathematical modelling. & $\begin{array}{l}\text { With metaheuristic model renewable energy, } \\
\text { source incorporation is easy. }\end{array}$ \\
\hline
\end{tabular}

turbine-integrated power system with wind uncertainty and correlated loads. In 2014, Lin and Lin [101] presented a risklimiting optimal power flow (RLOPF) problem for systems with high penetration of wind power, to address the problem of possibly violating the security constraints in power systems due to the instability of wind power generations. In 2014, Luo et al. [136] presented an energy storage sizing method for reliability requirement. Additionally, a bilevel control strategy for the isolated grids is proposed. In 2016, Mohammadi et al. [102] designed a state feedback controller (SFC) for damping oscillations and tracking the set point input as well as discarding the disturbances correctly for a variable wind system.
The suggested method reflects damping and performance together by including a performance index into linear quadratic (LQ) criterion. In 2016, Mohseni-Bonab et al. [103] presented the stochastic multiobjective optimal reactive power dispatch (SMO-ORPD) problem for wind integrated power system, taking into account the uncertainties of system load and wind power generations. In 2014, Panda and Tripathy [104] presented an OPF solution for modified power system in which three conventional generators are replaced by wind-energy conversion systems (WECS). To justify the limitation of reactive power generation capability of WECS, genetic algorithm (GA) and a modified bacteria 


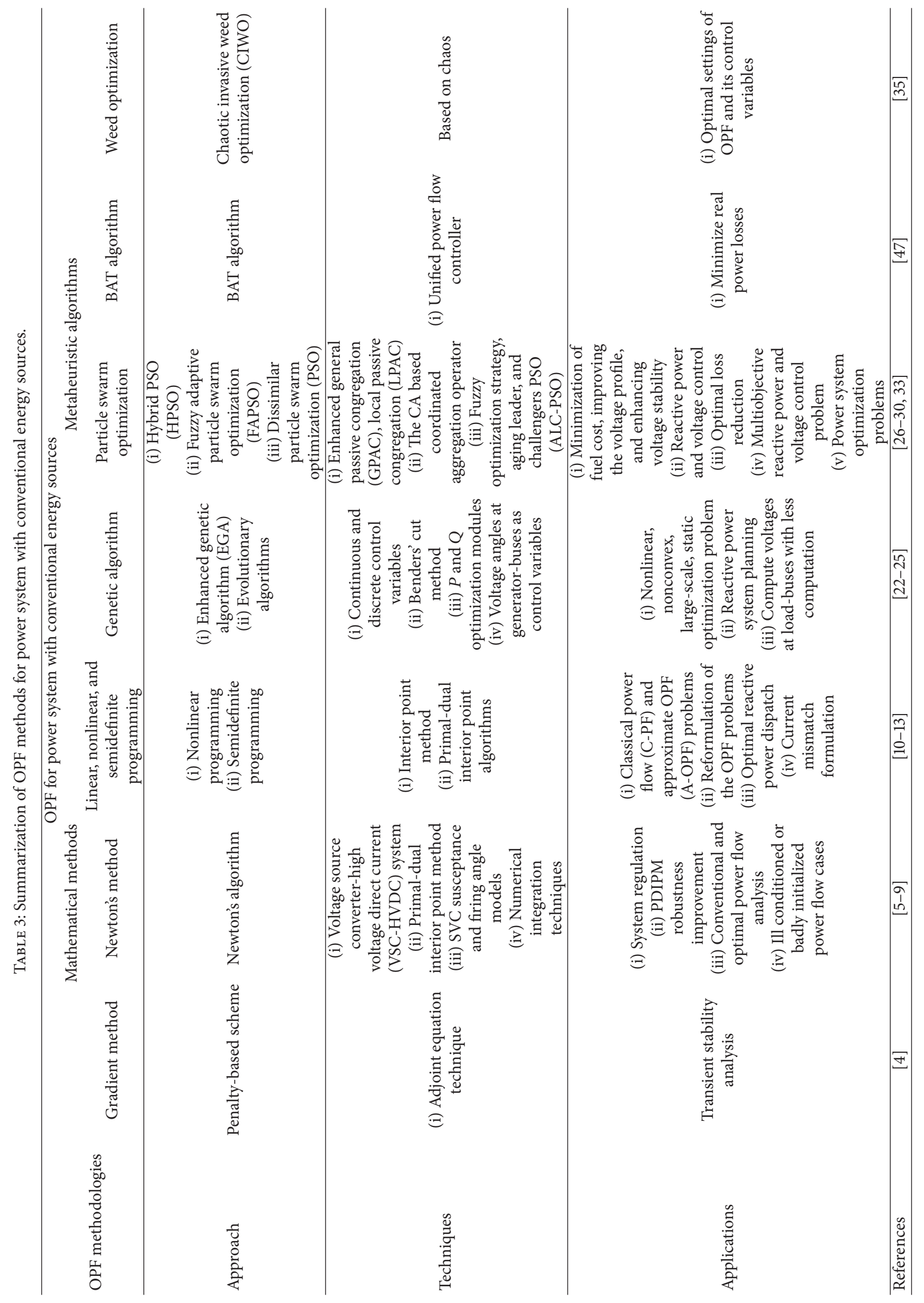




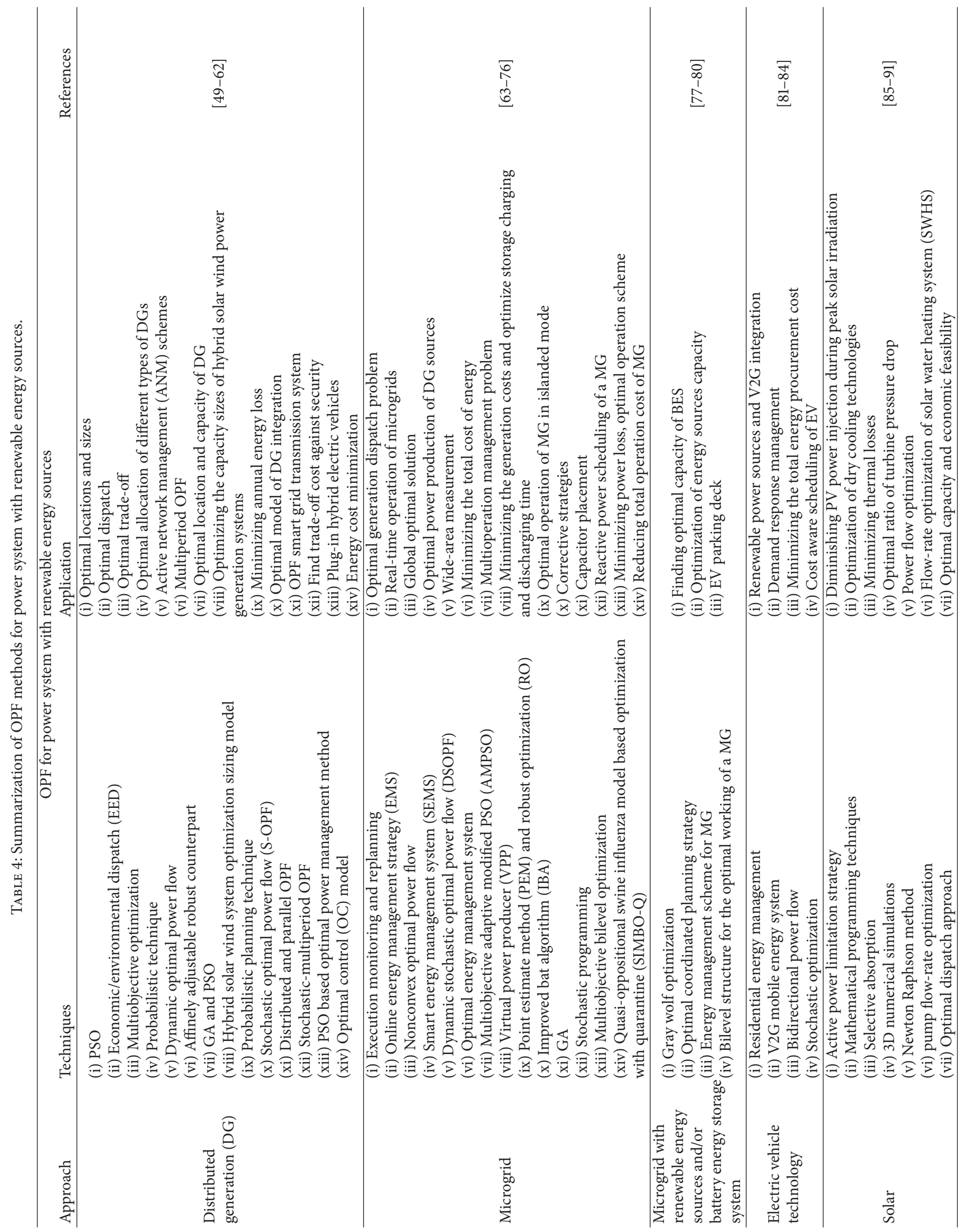




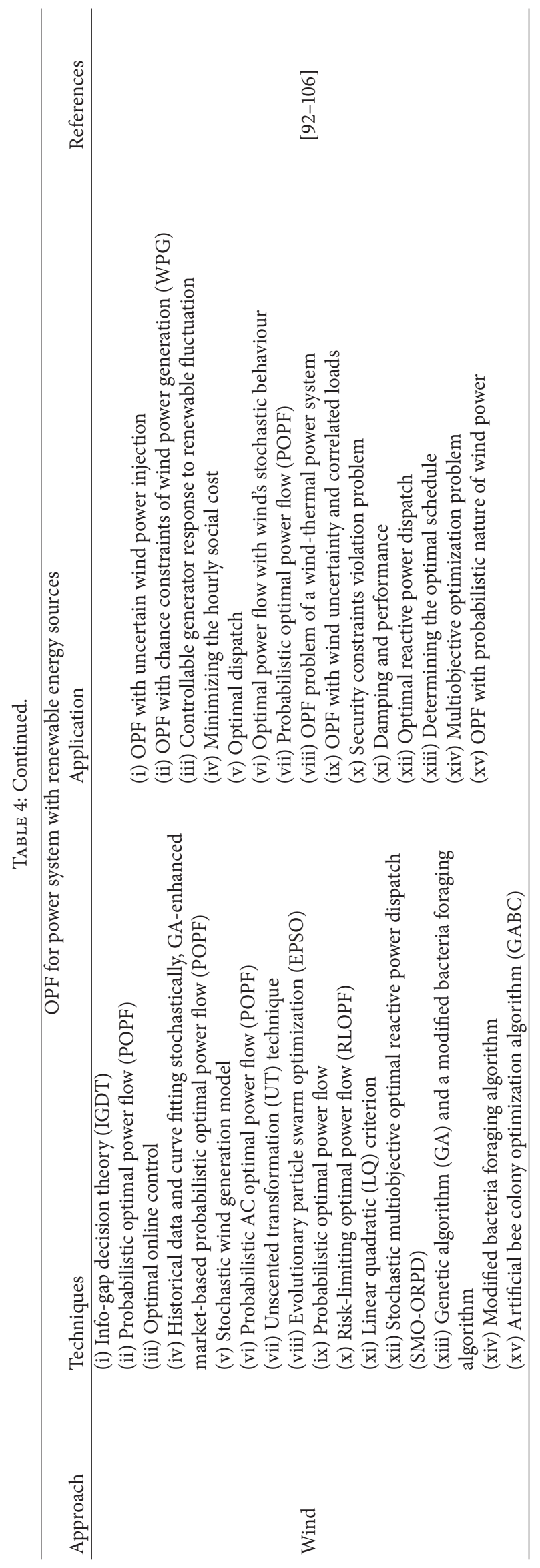


foraging algorithm are employed independently, for determining the optimal schedule. In 2015, Panda and Tripathy [105] presented a modified bacteria foraging algorithm, which is capable of handling multiobjective optimization problems. In 2015, Roald et al. [137] presented a technique of modelling risk in power system operation, accounting for the system availability of redispatch. The resulting risk measure formulates risk-based constraints for the postcontingency line flows. In 2015, Roy and Jadhav [106] presented an OPF study in view of probabilistic nature of wind power. The wind power intermittency is modelled by the parameters of Weibull probability function. The optimization problems are solved by artificial bee colony optimization algorithm (GABC).

\section{Comparative Analysis of OPF Methods}

This section presents a comparative analysis of different OPF methods, which are reviewed in the previous sections. Table 1 presents a comparative analysis of different OPF techniques.

Table 2 presents a comparison between traditional and metaheuristic technique based OPF methods used for the optimization of renewable energy sources.

A detailed summarization of the OPF methods for power system with conventional energy sources is presented in Table 3.

Table 4 presents a summarization of OPF methods for power system with renewable energy sources.

\section{Conclusions}

Optimal power flow is an optimizing tool for power system operation analysis, scheduling, and energy management. Use of the optimal power flow is becoming more important because of its capabilities to deal with various situations. This problem involves the optimization of an objective function that takes various forms while satisfying a set of operational and physical constraints. Hence, in this work authors present a comprehensive review of solution techniques and methods used for optimization of power flows. Further, techniques used for optimization of systems incorporating renewable energy sources such as microgrid, storage system, electrical vehicle, wind, and solar are also reviewed in this work. Different metaheuristic techniques used for OPF are further discussed. Different OPF problems are discussed with respect to the constraints applied and assumptions made. The traditional and metaheuristic based OPF techniques are compared with respect to different properties of OPF techniques. Different mathematical and metaheuristic algorithms used for OPF power system with conventional and renewable energy sources are discussed. A summarization of different techniques used for OPF with traditional and renewable energy sources is presented based on their adopted approach, techniques, and applications.

There are still many constraints and there is nonlinearity, which should be incorporated in future OPF problem. Problems related to mathematical validation, deregulated market constraints, contingencies incorporation, and renewable sources integration are latest challenges for future OPF problems. This study will assist researchers in comparing and selecting an appropriate OPF technique, to find the optimal state of any system under system constraint. This work may also be supportive for the commercial utilization of OPF. Additionally, other better techniques may also be considered for further study. The futuristic enrichment of the current study may be to develop a OPF technique, which can provide better results.

\section{Conflicts of Interest}

The authors declare that there are no conflicts of interest regarding the publication of this paper.

\section{References}

[1] J. Carpentier, “Optimal power flows," International Journal of Electrical Power \& Energy Systems, vol. 1, no. 1, pp. 3-15, 1979.

[2] H. W. Dommel and W. F. Tinney, "Optimal Power Flow Solutions," IEEE Transactions on Power Apparatus and Systems, vol. 87, no. 10, pp. 1866-1876, 1968.

[3] J. A. Momoh, R. J. Koessler, M. S. Bond et al., "Challenges to optimal power flow," IEEE Transactions on Power Systems, vol. 12, no. 1, pp. 444-447, 1997.

[4] Y. Sun, Y. Xinlin, and H. F. Wang, "Approach for optimal power flow with transient stability constraints," IEE Proceedings Generation, Transmission and Distribution, vol. 151, no. 1, pp. 818,2004

[5] D. I. Sun, B. Ashley, B. Brewer, A. Hughes, and W. F. Tinney, "Optimal power flow by Newton approach," IEEE Transactions on Power Apparatus and Systems, vol. 103, no. 10, pp. 2864-2880, 1984.

[6] A. Pizano-Martinez, C. R. Fuerte-Esquivel, H. Ambriz-Pérez, and E. Acha, "Modeling of VSC-based HVDC systems for a Newton-Raphson OPF algorithm," IEEE Transactions on Power Systems, vol. 22, no. 4, pp. 1794-1803, 2007.

[7] X. Zhao, Y. Yang, and H. Wei, "An interior point method based on continuous Newton's method for optimal power flow," in Proceedings of the IEEE Innovative Smart Grid Technologies, pp. 1-6, May 2012.

[8] H. Ambriz-Perez, E. Acha, and C. R. Fuerte-Esquivel, "Advanced SVC models for Newton-Raphson load flow and Newton optimal power flow studies," IEEE Transactions on Power Systems, vol. 15, no. 1, pp. 129-136, 2000.

[9] F. Milano, "Continuous Newton's method for power flow analysis," IEEE Transactions on Power Systems, vol. 24, no. 1, pp. 50$57,2009$.

[10] H. H. Wei, S. J. Kubokawa, and R. Yokoyama, "An interior point nonlinear programming for optimal power flow problems with a novel data Structure," IEEE Transactions on Power Systems, vol. 13, no. 3, pp. 870-877, 1998.

[11] X. Bai, H. Wei, K. Fujisawa, and Y. Wang, "Semidefinite programming for optimal power flow problems," International Journal of Electrical Power \& Energy Systems, vol. 30, no. 6-7, pp. 383-392, 2008.

[12] S. Granville, "Optimal reactive dispatch through interior point methods," IEEE Transactions on Power Systems, vol. 9, no. 1, pp. 136-146, 1994. 
[13] X. P. Zhang, S. G. Petoussis, and K. R. Godfrey, "Nonlinear interior-point optimal power flow method based on a current mismatch formulation," pp. 795-805.

[14] S. Y. Abdelouadoud, R. Girard, F. P. Neirac, and T. Guiot, "Optimal power flow of a distribution system based on increasingly tight cutting planes added to a second order cone relaxation," International Journal of Electrical Power \& Energy Systems, vol. 69, pp. 9-17, 2015.

[15] A. R. Baran and T. S. P. Fernandes, "A three-phase optimal power flow applied to the planning of unbalanced distribution networks," International Journal of Electrical Power \& Energy Systems, vol. 74, pp. 301-309, 2016.

[16] A. Garces, "A quadratic approximation for the optimal power flow in power distribution systems," Electric Power Systems Research, vol. 130, pp. 222-229, 2016.

[17] G. Emily Manoranjitham and A. Shunmugalatha, "Application of firefly algorithm on optimal power flow control incorporating simplified impedance UPFC model," International Journal of Electrical Power \& Energy Systems, vol. 71, pp. 358-363, 2015.

[18] Y. Xu, H. Yang, R. Zhang, Z. Y. Dong, M. Lai, and K. P. Wong, "A contingency partitioning approach for preventive-corrective security-constrained optimal power flow computation," Electric Power Systems Research, vol. 132, pp. 132-140, 2016.

[19] X. Zhang, T. Yu, B. Yang, L. Zheng, and L. Huang, "Approximate ideal multi-objective solution $\mathrm{Q}(\lambda)$ learning for optimal carbon-energy combined-flow in multi-energy power systems," Energy Conversion and Management, vol. 106, pp. 543-556, 2015.

[20] J. Zhao, L. Ju, Z. Dai, and G. Chen, "Voltage stability constrained dynamic optimal reactive power flow based on branch-bound and primal-dual interior point method," International Journal of Electrical Power \& Energy Systems, vol. 73, pp. 601-607, 2015.

[21] Q. Wang, J. D. McCalley, T. Zheng, and E. Litvinov, "Solving corrective risk-based security-constrained optimal power flow with Lagrangian relaxation and Benders decomposition," International Journal of Electrical Power \& Energy Systems, vol. 75, pp. 255-264, 2016.

[22] A. G. Bakirtzis, P. N. Biskas, C. E. Zoumas, and V. Petridis, "Optimal power flow by enhanced genetic algorithm," IEEE Transactions on Power Systems, vol. 17, no. 2, pp. 229-236, 2002.

[23] K. Y. Lee, X. Bai, and Y.-M. Park, "Optimization Method for Reactive Power Planning by Using a Modified Simple Genetic Algorithm," IEEE Transactions on Power Systems, vol. 10, no. 4, pp. 1843-1850, 1995.

[24] K. Y. Lee, “Optimal reactive power planning using evolutionary algorithms: a comparative study for evolutionary programming, evolutionary strategy, genetic algorithm, and linear programming," IEEE Transactions on Power Systems, vol. 13, no. 1, pp. 101-108, 1998.

[25] M. Todorovski and D. Rajicic, "An initialization procedure in solving optimal power flow by genetic algorithm," IEEE Transactions on Power Systems, vol. 21, no. 2, pp. 480-487, 2006.

[26] M. A. Abido, "Optimal power flow using particle swarm optimization," International Journal of Electrical Power \& Energy Systems, vol. 24, no. 7, pp. 563-571, 2002.

[27] J. G. Vlachogiannis and K. Y. Lee, "A comparative study on particle swarm optimization for optimal steady-state performance of power systems," IEEE Transactions on Power Systems, vol. 21, no. 4, pp. 1718-1728, 2006.

[28] A. A. A. Esmin, G. Lambert-Torres, and A. C. Zambroni de Souza, "A hybrid particle swarm optimization applied to loss power minimization," IEEE Transactions on Power Systems, vol. 20, no. 2, pp. 859-866, 2005.

[29] W. Zhang and Y. T. Liu, "Multi-objective reactive power and voltage control based on fuzzy optimization strategy and fuzzy adaptive particle swarm," International Journal of Electrical Power \& Energy Systems, vol. 30, no. 9, pp. 525-532, 2008.

[30] M. R. Al-Rashidi and M. E. El-Hawary, "A survey of particle swarm optimization applications in electric power systems," IEEE Transactions on Evolutionary Computation, vol. 13, no. 4, pp. 913-918, 2009.

[31] X. Su, M. A. S. Masoum, and P. J. Wolfs, "PSO and improved BSFS based sequential comprehensive placement and real-time multi-objective control of delta-connected switched capacitors in unbalanced radial MV distribution networks," IEEE Transactions on Power Systems, vol. 31, no. 1, pp. 612-622, 2016.

[32] Y. del Valle, G. K. Venayagamoorthy, S. Mohagheghi, J.-C. Hernandez, and R. G. Harley, "Particle swarm optimization: basic concepts, variants and applications in power systems," IEEE Transactions on Evolutionary Computation, vol. 12, no. 2, pp. 171-195, 2008.

[33] R. P. Singh, V. Mukherjee, and S. P. Ghoshal, "Particle swarm optimization with an aging leader and challengers algorithm for the solution of optimal power flow problem," Applied Soft Computing, vol. 40, pp. 161-177, 2016.

[34] T. Niknam, M. R. Narimani, M. Jabbari, and A. R. Malekpour, "A modified shuffle frog leaping algorithm for multi-objective optimal power flow," Energy, vol. 36, no. 11, pp. 6420-6432, 2011.

[35] M. Ghasemi, S. Ghavidel, E. Akbari, and A. A. Vahed, "Solving non-linear, non-smooth and non-convex optimal power flow problems using chaotic invasive weed optimization algorithms based on chaos," Energy, vol. 73, pp. 340-353, 2014.

[36] K. Abaci and V. Yamacli, "Differential search algorithm for solving multi-objective optimal power flow problem," International Journal of Electrical Power \& Energy Systems, vol. 79, pp. 1-10, 2016.

[37] P. Acharjee, "Optimal power flow with UPFC using security constrained self-adaptive differential evolutionary algorithm for restructured power system," International Journal of Electrical Power \& Energy Systems, vol. 76, pp. 69-81, 2016.

[38] R. Ardeshiri Lajimi and T. Amraee, "A two stage model for rotor angle transient stability constrained optimal power flow," International Journal of Electrical Power \& Energy Systems, vol. 76, pp. 82-89, 2016.

[39] K. Ayan and U. Kiliç, "Optimal power flow of two-terminal HVDC systems using backtracking search algorithm," International Journal of Electrical Power \& Energy Systems, vol. 78, pp. 326-335, 2016.

[40] N. Daryani, M. T. Hagh, and S. Teimourzadeh, "Adaptive group search optimization algorithm for multi-objective optimal power flow problem," Applied Soft Computing, vol. 38, pp. 1012-1024, 2016.

[41] B. Mahdad and K. Srairi, "Security optimal power flow considering loading margin stability using hybrid FFA-PS assisted with brainstorming rules," Applied Soft Computing, vol. 35, article no. 3031, pp. 291-309, 2015.

[42] A. Mukherjee, "Solution of optimal power flow using chaotic krill herd algorithm," Chaos, Solitons \& Fractals, vol. 78, pp. 1021, 2015.

[43] A. Mukherjee and V. Mukherjee, "Solution of optimal power flow with FACTS devices using a novel oppositional krill herd 
algorithm," International Journal of Electrical Power \& Energy Systems, vol. 78, pp. 700-714, 2016.

[44] K. Pandiarajan and C. K. Babulal, "Fuzzy harmony search algorithm based optimal power flow for power system security enhancement," International Journal of Electrical Power \& Energy Systems, vol. 78, pp. 72-79, 2016.

[45] D. Prasad and V. Mukherjee, "A novel symbiotic organisms search algorithm for optimal power flow of power system with FACTS devices," Engineering Science \& Technology, vol. 19, no. 1, pp. 79-89, 2016.

[46] A. Ramesh Kumar and L. Premalatha, "Optimal power flow for a deregulated power system using adaptive real coded biogeography-based optimization," International Journal of Electrical Power \& Energy Systems, vol. 73, article no. 3472, pp. 393399, 2015.

[47] B. Venkateswara Rao and G. V. Nagesh Kumar, "Optimal power flow by BAT search algorithm for generation reallocation with unified power flow controller," International Journal of Electrical Power \& Energy Systems, vol. 68, pp. 81-88, 2015.

[48] X. Yuan, P. Wang, Y. Yuan, Y. Huang, and X. Zhang, "A new quantum inspired chaotic artificial bee colony algorithm for optimal power flow problem," Energy Conversion and Management, vol. 100, pp. 1-9, 2015.

[49] O. Amanifar and M. E. Hamedani Golshan, "Optimal Distributed Generation Placement and Sizing for Loss and THD Reduction and Voltage Profile Improvement," Technical and Physical Problems of Engineering (IJTPE), vol. 3, no. 2, 2011.

[50] F. R. Pazheri, M. F. Othman, N. H. Malik, and S. O. K, "Economic and Environmental Dispatch at Highly Potential Renewable Area with Renewable Storage," International Journal of Environmental Science and Development, pp. 177-182, 2012.

[51] M. Nick, R. Cherkaoui, and M. Paolone, "Optimal allocation of dispersed energy storage systems in active distribution networks for energy balance and grid support," IEEE Transactions on Power Systems, vol. 29, no. 5, pp. 2300-2310, 2014.

[52] Y. M. Atwa, E. F. El-Saadany, M. M. A. Salama, and R. Seethapathy, "Optimal renewable resources mix for distribution system energy loss minimization," IEEE Transactions on Power Systems, vol. 25, no. 1, pp. 360-370, 2010.

[53] S. Gill, I. Kockar, and G. W. Ault, "Dynamic optimal power flow for active distribution networks," IEEE Transactions on Power Systems, vol. 29, no. 1, pp. 121-131, 2014.

[54] R. A. Jabr, S. Karaki, and J. A. Korbane, "Robust Multi-Period OPF with Storage and Renewables," IEEE Transactions on Power Systems, vol. 30, no. 5, pp. 2790-2799, 2015.

[55] M. H. Moradi and M. Abedini, "A combination of genetic algorithm and particle swarm optimization for optimal DG location and sizing in distribution systems," International Journal of Electrical Power \& Energy Systems, vol. 34, no. 1, pp. 66-74, 2012.

[56] H. Yang, L. Lu, and W. Zhou, "A novel optimization sizing model for hybrid solar-wind power generation system," Solar Energy, vol. 81, no. 1, pp. 76-84, 2007.

[57] Y. M. Atwa and E. F. El-Saadany, "Probabilistic approach for optimal allocation of wind-based distributed generation in distribution systems," IET Renewable Power Generation, vol. 5, no. 1, pp. 79-88, 2011.

[58] C. Wei, Y. Fu, Z. Li, and Y. Jiang, "Optimal DG penetration rate planning based on S-OPF in active distribution network," Neurocomputing, vol. 174, pp. 514-521, 2016.
[59] S.-Y. Lin and J.-F. Chen, "Distributed optimal power flow for smart grid transmission system with renewable energy sources," Energy, vol. 56, pp. 184-192, 2013.

[60] T. Summers, J. Warrington, M. Morari, and J. Lygeros, “Stochastic optimal power flow based on conditional value at risk and distributional robustness," International Journal of Electrical Power \& Energy Systems, vol. 72, pp. 116-125, 2015.

[61] Z. Chen, R. Xiong, and J. Cao, "Particle swarm optimizationbased optimal power management of plug-in hybrid electric vehicles considering uncertain driving conditions," Energy, vol. 96, pp. 197-208, 2016.

[62] S. Sichilalu, T. Mathaba, and X. Xia, "Optimal control of a wind-PV-hybrid powered heat pump water heater," Applied Energy, vol. 185, pp. 1173-1184, 2017.

[63] E. R. Sanseverino, M. L. Di Silvestre, M. G. Ippolito, A. De Paola, and G. Lo Re, "An execution, monitoring and replanning approach for optimal energy management in microgrids," Energy, vol. 36, no. 5, pp. 3429-3436, 2011.

[64] W. Shi, N. Li, C. Chu, and R. Gadh, "Real-Time Energy Management in Micro grids," IEEE Transactions on Smart Grid, no. 99, pp. 1-1, 2015.

[65] E. Dall'Anese, H. Zhu, and G. B. Giannakis, "Distributed optimal power flow for smart microgrids," IEEE Transactions on Smart Grid, vol. 4, no. 3, pp. 1464-1475, 2013.

[66] C. Chen, S. Duan, T. Cai, B. Liu, and G. Hu, "Smart energy management system for optimal microgrid economic operation," IET Renewable Power Generation, vol. 5, no. 3, pp. 258-267, 2011.

[67] J. Liang, G. K. Venayagamoorthy, and R. G. Harley, "Wide-area measurement based dynamic stochastic optimal power flow control for smart grids with high variability and uncertainty," IEEE Transactions on Smart Grid, vol. 3, no. 1, pp. 59-69, 2012.

[68] Y. Levron, J. M. Guerrero, and Y. Beck, "Optimal power flow in microgrids with energy storage," IEEE Transactions on Power Systems, vol. 28, no. 3, pp. 3226-3234, 2013.

[69] A. A. Moghaddam, A. Seifi, T. Niknam, and M. R. Alizadeh Pahlavani, "Multi-objective operation management of a renewable MG (micro-grid) with back-up micro-turbine/fuel cell/ battery hybrid power source," Energy, vol. 36, no. 11, pp. 64906507, 2011.

[70] H. Morais, P. Kádár, P. Faria, Z. A. Vale, and H. M. Khodr, “Optimal scheduling of a renewable micro-grid in an isolated load area using mixed-integer linear programming," Journal of Renewable Energy, vol. 35, no. 1, pp. 151-156, 2010.

[71] S. A. Alavi, A. Ahmadian, and M. Aliakbar-Golkar, "Optimal probabilistic energy management in a typical micro-grid basedon robust optimization and point estimate method," Energy Conversion and Management, vol. 95, pp. 314-325, 2015.

[72] B. Bahmani-Firouzi and R. Azizipanah-Abarghooee, "Optimal sizing of battery energy storage for micro-grid operation management using a new improved bat algorithm," International Journal of Electrical Power \& Energy Systems, vol. 56, pp. 42-54, 2014.

[73] R. Gholami, M. Shahabi, and M. R. Haghifam, "An efficient optimal capacitor allocation in DG embedded distribution networks with islanding operation capability of micro-grid using a new genetic based algorithm," International Journal of Electrical Power \& Energy Systems, vol. 71, pp. 335-343, 2015.

[74] B. Khorramdel and M. Raoofat, "Optimal stochastic reactive power scheduling in a microgrid considering voltage droop scheme of DGs and uncertainty of wind farms," Energy, vol. 45, no. 1, pp. 994-1006, 2012. 
[75] T. Lv, Q. Ai, and Y. Zhao, "A bi-level multi-objective optimal operation of grid-connected microgrids," Electric Power Systems Research, vol. 131, pp. 60-70, 2016.

[76] S. Sharma, S. Bhattacharjee, and A. Bhattacharya, "Operation cost minimization of a Micro-Grid using Quasi-Oppositional Swine Influenza Model Based Optimization with Quarantine," Ain Shams Engineering Journal, 2015.

[77] S. Sharma, S. Bhattacharjee, and A. Bhattacharya, "Grey wolf optimisation for optimal sizing of battery energy storage device to minimise operation cost of microgrid," IET Generation, Transmission \& Distribution, vol. 10, no. 3, pp. 625-637, 2016.

[78] Z. Liu, Y. Chen, Y. Luo, G. Zhao, and X. Jin, "Optimized planning of power source capacity in microgrid, considering combinations of energy storage devices," Applied Sciences (Switzerland), vol. 6, no. 12, article no. 416, 2016.

[79] J. Shen, C. Jiang, Y. Liu, and X. Wang, "A Microgrid Energy Management System and Risk Management under an Electricity Market Environment," IEEE Access, vol. 4, pp. 2349-2356, 2016.

[80] Y. Guo, J. Xiong, S. Xu, and W. Su, "Two-Stage Economic Operation of Microgrid-Like Electric Vehicle Parking Deck," IEEE Transactions on Smart Grid, vol. 7, no. 3, pp. 1703-1712, 2016.

[81] F. Y. Melhem, N. Moubayed, and O. Grunder, "Residential energy management in smart grid considering renewable energy sources and vehicle-to-grid integration," in Proceedings of the 2016 IEEE Electrical Power and Energy Conference, EPEC 2016, can, October 2016.

[82] R. Yu, W. Zhong, S. Xie, C. Yuen, S. Gjessing, and Y. Zhang, "Balancing Power Demand Through EV Mobility in Vehicle-toGrid Mobile Energy Networks," IEEE Transactions on Industrial Informatics, vol. 12, no. 1, pp. 79-90, 2016.

[83] N. G. Paterakis, O. Erdinc, I. N. Pappi, A. G. Bakirtzis, and J. P. S. Catalao, "Coordinated Operation of a Neighborhood of Smart Households Comprising Electric Vehicles, Energy Storage and Distributed Generation," IEEE Transactions on Smart Grid, vol. 7, no. 6, pp. 2736-2747, 2016.

[84] G. Li, D. Wu, J. Hu, Y. Li, M. S. Hossain, and A. Ghoneim, "HELOS: Heterogeneous Load Scheduling for Electric VehicleIntegrated Microgrids," IEEE Transactions on Vehicular Technology, vol. 66, no. 7, pp. 5785-5796, 2017.

[85] C.-H. Lin, W.-L. Hsieh, C.-S. Chen, C.-T. Hsu, and T.-T. $\mathrm{Ku}$, "Optimization of photovoltaic penetration in distribution systems considering annual duration curve of solar irradiation," IEEE Transactions on Power Systems, vol. 27, no. 2, pp. 10901097, 2012.

[86] M. Martín, "Optimal annual operation of the dry cooling system of a concentrated solar energy plant in the south of Spain," Energy, vol. 84, pp. 774-782, 2015.

[87] K. Burlafinger, A. Vetter, and C. J. Brabec, "Maximizing concentrated solar power (CSP) plant overall efficiencies by using spectral selective absorbers at optimal operation temperatures," Solar Energy, vol. 120, pp. 428-438, 2015.

[88] P. Guo, J. Li, Y. Wang, and Y. Wang, "Evaluation of the optimal turbine pressure drop ratio for a solar chimney power plant," Energy Conversion and Management, vol. 108, pp. 14-22, 2016.

[89] R. Nazir, K. Kanada, Syafii, and P. Coveria, "Optimization active and reactive power flow for PV connected to grid system using Newton Raphson method," in Proceedings of the 2nd International Conference on Sustainable Energy Engineering and Application, ICSEEA 2014, pp. 77-86, idn, October 2014.
[90] S. Ntsaluba, B. Zhu, and X. Xia, "Optimal flow control of a forced circulation solar water heating system with energy storage units and connecting pipes," Journal of Renewable Energy, vol. 89, pp. 108-124, 2016.

[91] G. Wang, M. Ciobotaru, and V. G. Agelidis, "Optimal capacity design for hybrid energy storage system supporting dispatch of large-scale photovoltaic power plant," Journal of Energy Storage, vol. 3, pp. 25-35, 2015.

[92] A. Rabiee, A. Soroudi, and A. Keane, "Information gap decision theory based OPF with HVDC connected wind farms," IEEE Transactions on Power Systems, vol. 30, no. 6, pp. 3396-3406, 2014.

[93] D. Ke, C. Y. Chung, and Y. Sun, "A novel probabilistic optimal power flow model with uncertain wind power generation described by customized Gaussian mixture model," IEEE Transactions on Sustainable Energy, vol. 7, no. 1, pp. 200-212, 2016.

[94] D. Bienstock, M. Chertkov, and S. Harnett, "Chanceconstrained optimal power flow: risk-aware network control under uncertainty," SIAM Review, vol. 56, no. 3, pp. 461-495, 2014.

[95] M. Ghofrani, A. Arabali, M. Etezadi-Amoli, and M. S. Fadali, "A framework for optimal placement of energy storage units within a power system with high wind penetration," IEEE Transactions on Sustainable Energy, vol. 4, no. 2, pp. 434-442, 2013.

[96] R. A. Jabr and B. C. Pal, "Intermittent wind generation in optimal power flow dispatching," IET Generation, Transmission \& Distribution, vol. 3, no. 1, pp. 66-74, 2009.

[97] G. J. Sebastián, C. J. Alexander, and G. Mauricio, “Stochastic AC Optimal Power Flow Considering the Probabilistic Behavior of the Wind, Loads and Line Parameters," Ingeniería, Investigación y Tecnología, vol. 15, no. 4, pp. 529-538, 2014.

[98] M. Aien, M. Rashidinejad, and M. F. Firuz-Abad, "Probabilistic optimal power flow in correlated hybrid wind-PV power systems: A review and a new approach," Renewable \& Sustainable Energy Reviews, vol. 41, pp. 1437-1446, 2015.

[99] Y.-C. Chang, T.-Y. Lee, C.-L. Chen, and R.-M. Jan, "Optimal power flow of a wind-thermal generation system," International Journal of Electrical Power \& Energy Systems, vol. 55, pp. 312320, 2014.

[100] X. Li, J. Cao, and D. Du, "Probabilistic optimal power flow for power systems considering wind uncertainty and load correlation," Neurocomputing, vol. 148, pp. 240-247, 2015.

[101] S.-Y. Lin and A.-C. Lin, "RLOPF (risk-limiting optimal power flow) for systems with high penetration of wind power," Energy, vol. 71, pp. 49-61, 2014.

[102] A. Mohammadi, S. Tavakoli, and S. M. Barakati, "On power tracking and alleviation by a new controller for fulfilment of the damping and performance requisites for a variable speed wind system: An optimal approach," International Journal of Electrical Power \& Energy Systems, vol. 75, pp. 187-193, 2016.

[103] S. M. Mohseni-Bonab, A. Rabiee, and B. Mohammadi-Ivatloo, "Voltage stability constrained multi-objective optimal reactive power dispatch under load and wind power uncertainties: A stochastic approach," Journal of Renewable Energy, vol. 85, pp. 598-609, 2016.

[104] A. Panda and M. Tripathy, "Optimal power flow solution of wind integrated power system using modified bacteria foraging algorithm," International Journal of Electrical Power \& Energy Systems, vol. 54, pp. 306-314, 2014. 
[105] A. Panda and M. Tripathy, "Security constrained optimal power flow solution of wind-thermal generation system using modified bacteria foraging algorithm," Energy, vol. 93, pp. 816-827, 2015.

[106] R. Roy and H. T. Jadhav, "Optimal power flow solution of power system incorporating stochastic wind power using Gbest guided artificial bee colony algorithm," International Journal of Electrical Power \& Energy Systems, vol. 64, pp. 562-578, 2015.

[107] G. P. Harrison and A. R. Wallace, "Optimal power flow evaluation of distribution network capacity for the connection of distributed generation," in Proceedings of the IEE Proc.-Gener. Transm. Distrib., pp. 115-122, 2005.

[108] P. S. Georgilakis and N. D. Hatziargyriou, "Optimal distributed generation placement in power distribution networks: models, methods, and future research," IEEE Transactions on Power Systems, vol. 28, no. 3, pp. 3420-3428, 2013.

[109] E. Sortomme and M. A. El-Sharkawi, "Optimal charging strategies for unidirectional vehicle-to-grid," IEEE Transactions on Smart Grid, vol. 2, no. 1, pp. 131-138, 2011.

[110] S. Ashok, "Optimised model for community-based hybrid energy system," Journal of Renewable Energy, vol. 32, no. 7, pp. 1155-1164, 2007.

[111] A. S. Bouhouras, K. I. Sgouras, P. A. Gkaidatzis, and D. P. Labridis, "Optimal active and reactive nodal power requirements towards loss minimization under reverse power flow constraint defining DG type," International Journal of Electrical Power \& Energy Systems, vol. 78, pp. 445-454, 2016.

[112] R. Azizipanah-Abarghooee, T. Niknam, M. Malekpour, F. Bavafa, and M. Kaji, "Optimal power flow based TU/CHP/ PV/WPP coordination in view of wind speed, solar irradiance and load correlations," Energy Conversion and Management, vol. 96, pp. 131-145, 2015.

[113] H. Tazvinga, B. Zhu, and X. Xia, "Optimal power flow management for distributed energy resources with batteries," Energy Conversion and Management, vol. 102, 2016.

[114] T. Ma, H. Yang, L. Lu, and J. Peng, "Optimal design of an autonomous solar-wind-pumped storage power supply system," Applied Energy, vol. 160, pp. 728-736, 2015.

[115] C. Battistelli, L. Baringo, and A. J. Conejo, "Optimal energy management of small electric energy systems including V2G facilities and renewable energy sources," Electric Power Systems Research, vol. 92, pp. 50-59, 2012.

[116] K. Tanaka, K. Uchida, K. Ogimi et al., "Optimal operation by controllable loads based on smart grid topology considering insolation forecasted error," IEEE Transactions on Smart Grid, vol. 2, no. 3, pp. 438-444, 2011.

[117] A. Bracale, P. Caramia, G. Carpinelli, E. Mancini, and F. Mottola, "Optimal control strategy of a DC micro grid," International Journal of Electrical Power \& Energy Systems, vol. 67, pp. 25-38, 2015.

[118] D. McLarty, C. Civit Sabate, J. Brouwer, and F. Jabbari, "Microgrid energy dispatch optimization and predictive control algorithms; A UC Irvine case study," International Journal of Electrical Power \& Energy Systems, vol. 65, pp. 179-190, 2015.

[119] E. Riva Sanseverino, N. Nguyen Quang, M. L. Di Silvestre, J. M. Guerrero, and C. Li, "Optimal power flow in three-phase islanded microgrids with inverter interfaced units," Electric Power Systems Research, vol. 123, pp. 48-56, 2015.

[120] C. C. Thompson, P. E. Konstantinos Oikonomou, A. H. Etemadi, and V. J. Sorger, "Optimization of Data Center Battery
Storage Investments for Microgrid Cost Savings, Emissions Reduction, and Reliability Enhancement," IEEE Transactions on Industry Applications, vol. 52, no. 3, pp. 2053-2060, 2016.

[121] V. Krishnamurthy and A. Kwasinski, "Effects of Power Electronics, Energy Storage, Power Distribution Architecture, and Lifeline Dependencies on Microgrid Resiliency during Extreme Events," IEEE Journal of Emerging and Selected Topics in Power Electronics, vol. 4, no. 4, pp. 1310-1323, 2016.

[122] X. Xu, M. Bishop, O. Donna G, and H. Chen, "Application and modeling of battery energy storage in power systems," CSEE Journal of Power and Energy Systems, vol. 2, no. 3, pp. 82-90, 2016.

[123] R. Khodabakhsh and S. Sirouspour, "Optimal Control of Energy Storage in a Microgrid by Minimizing Conditional Value-atRisk," IEEE Transactions on Sustainable Energy, vol. 7, no. 3, pp. 1264-1273, 2016.

[124] H. Hassanzadehfard, S. M. Moghaddas-Tafreshi, and S. M. Hakimi, "Optimization of grid-connected microgrid consisting of PV/FC/UC with considered frequency control," Turkish Journal of Electrical Engineering \& Computer Sciences, vol. 23, no. 1, pp. 1-16, 2015.

[125] H. Alharbi and K. Bhattacharya, "Optimal sizing of battery energy storage systems for microgrids," in Proceedings of the 2014 Electrical Power and Energy Conference, EPEC 2014, pp. 275-280, November 2014.

[126] F. Laureri, L. Puliga, M. Robba, F. Delfino, and G. Odena Bultò, "An optimization model for the integration of electric vehicles and smart grids Problem definition and experimental validation," in Proceedings of the 2nd IEEE International Smart Cities Conference, ISC2 2016, September 2016.

[127] L. Yao, W. H. Lim, and T. S. Tsai, "A Real-Time Charging Scheme for Demand Response in Electric Vehicle Parking Station," IEEE Transactions on Smart Grid, vol. 8, no. 1, pp. 52-62, 2017.

[128] M. Bianchi, L. Branchini, C. Ferrari, and F. Melino, "Optimal sizing of grid-independent hybrid photovoltaic-battery power systems for household sector," Applied Energy, vol. 136, pp. 805816, 2014.

[129] Q. P. Ha and V. Vakiloroaya, "Modeling and optimal control of an energy-efficient hybrid solar air conditioning system," Automation in Construction, vol. 49, pp. 262-270, 2015.

[130] E. Lizarraga-Garcia, A. Ghobeity, M. Totten, and A. Mitsos, "Optimal operation of a solar-thermal power plant with energy storage and electricity buy-back from grid," Energy, vol. 51, pp. 61-70, 2013.

[131] E. M. A. Mokheimer, Y. N. Dabwan, and M. A. Habib, "Optimal integration of solar energy with fossil fuel gas turbine cogeneration plants using three different CSP technologies in Saudi Arabia," Applied Energy, vol. 185, pp. 1268-1280, 2017.

[132] T. K. A. Brekken, A. Yokochi, A. von Jouanne, Z. Z. Yen, H. M. Hapke, and D. A. Halamay, "Optimal energy storage sizing and control for wind power applications," IEEE Transactions on Sustainable Energy, vol. 2, no. 1, pp. 69-77, 2011.

[133] M. Sedghi, A. Ahmadian, and M. Aliakbar-Golkar, "Optimal storage planning in active distribution network considering uncertainty of wind power distributed generation," IEEE Transactions on Power Systems, vol. 31, no. 1, pp. 304-316, 2016.

[134] A. Arabali, M. Ghofrani, and M. Etezadi-Amoli, "Cost analysis of a power system using probabilistic optimal power flow with energy storage integration and wind generation," International Journal of Electrical Power \& Energy Systems, vol. 53, pp. 832841, 2013. 
[135] H. T. Jadhav and R. Roy, "Stochastic optimal power flow incorporating offshore wind farm and electric vehicles," International Journal of Electrical Power \& Energy Systems, vol. 69, pp. 173-187, 2015.

[136] Y. Luo, L. Shi, and G. Tu, "Optimal sizing and control strategy of isolated grid with wind power and energy storage system," Energy Conversion and Management, vol. 80, pp. 407-415, 2014.

[137] L. Roald, M. Vrakopoulou, F. Oldewurtel, and G. Andersson, "Risk-based optimal power flow with probabilistic guarantees," International Journal of Electrical Power \& Energy Systems, vol. 72, pp. 66-74, 2015. 


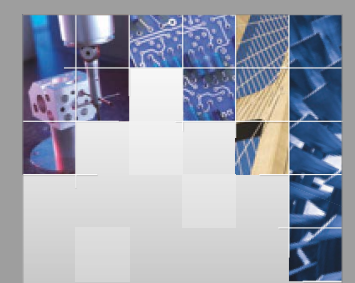

\section{Enfincering}
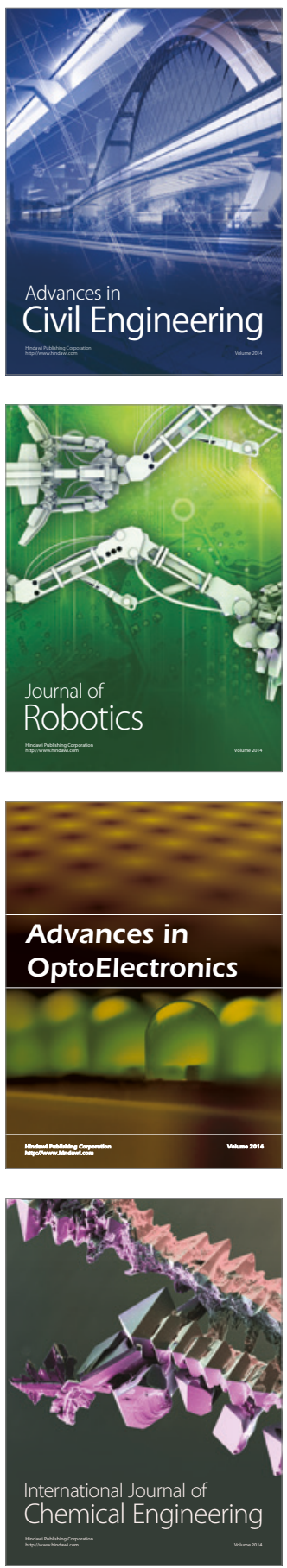

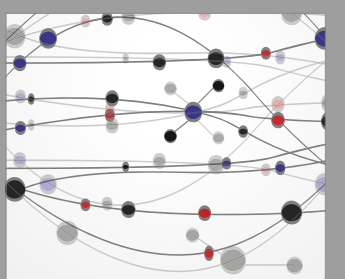

The Scientific World Journal

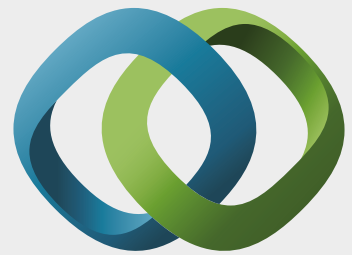

\section{Hindawi}

Submit your manuscripts at

https://www.hindawi.com
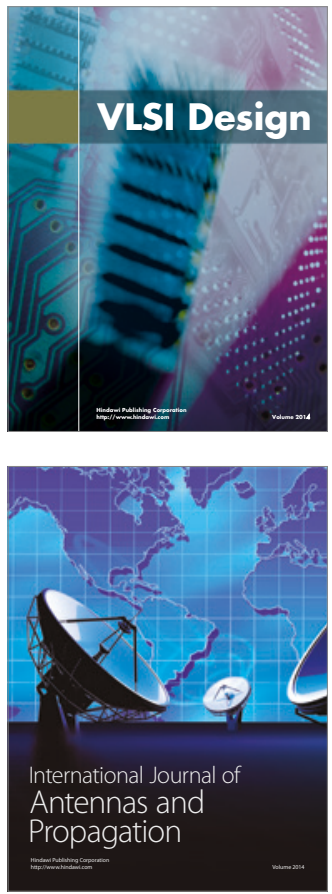

\section{Rotating}

Machinery
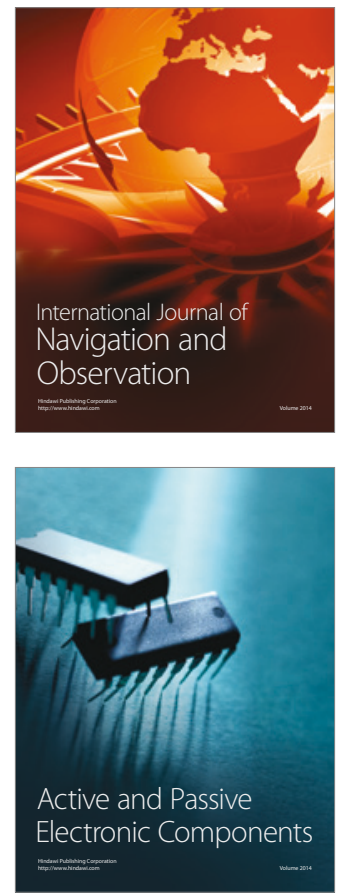
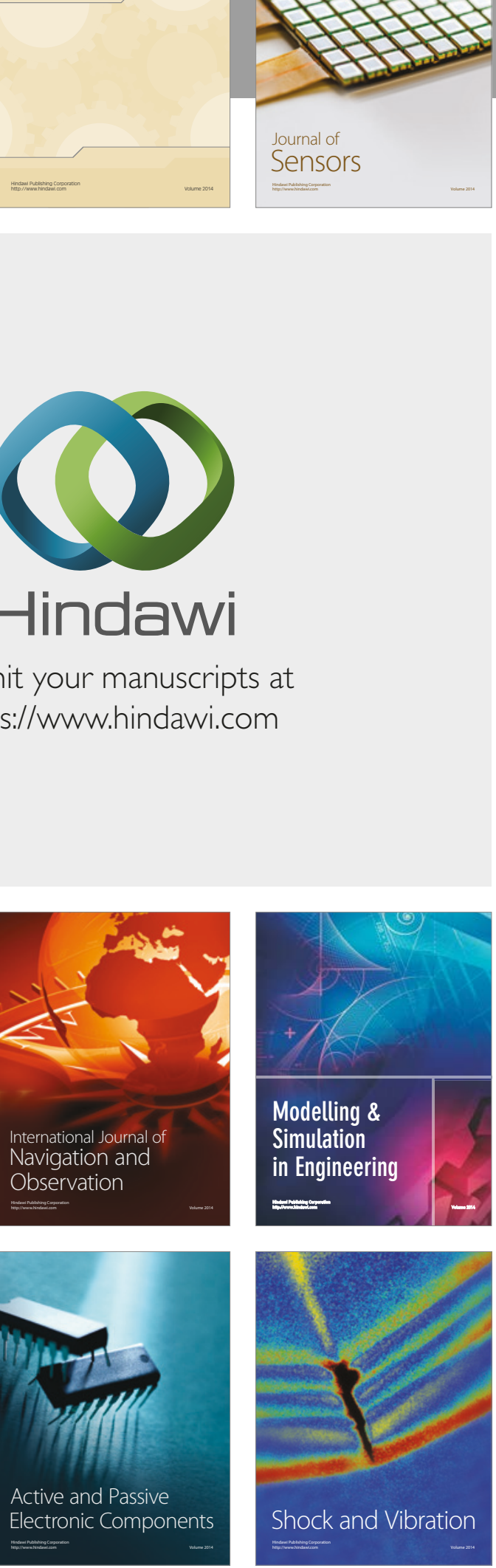
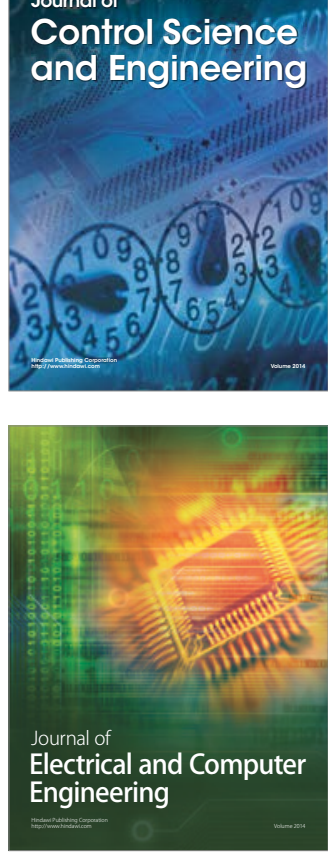

Distributed

Journal of

Control Science

and Engineering
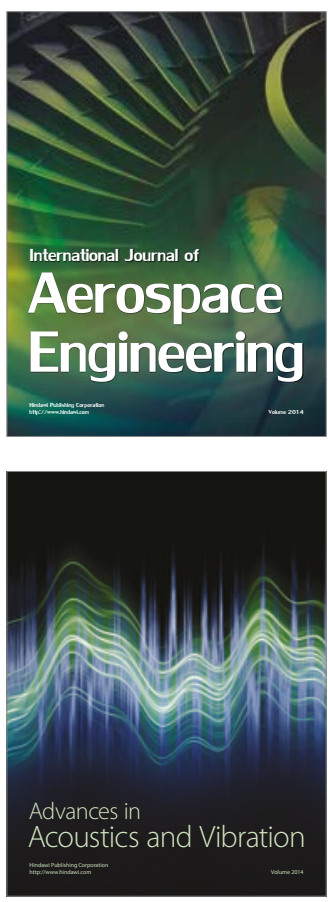

Sensor Networks 